\title{
Dependence of the Total Response Time of the LC Light Modulator on the Value of the Control Voltage
}

\author{
Georgy Simonenko V* \\ National Research Saratov State University of NG Chernyshevsky, 83 Astrakhanskaya St., Saratov, 410012, Russia
}

Submission: February 04, 2021; Published: February 10, 2021

*Corresponding author: Georgy Simonenko V, National Research Saratov State University of NG Chernyshevsky, 83 Astrakhanskaya St, Saratov, 410012, Russia

Abstract

The analytical dependence of the total response time of the LC light modulator on the control voltage was found using computer simulation. It is shown that there is a limiting value of the control voltage, upon reaching which its further increase does not lead to a decrease in the total response time of the device.

Keywords: Liquid crystals; Modulator; Computer modeling

\section{Introduction}

Currently, liquid crystals (LC) have found wide application in various systems for displaying and converting information [1]. The main problem of such systems for converting information is their relatively low speed, therefore, considerable efforts of researchers are aimed at finding ways to overcome this drawback. At the same time, high-speed LC systems based on nematic LC are in great demand. Today, several possible ways are proposed to increase the speed of such systems: changing the liquid crystal of a substance by introducing various particles into it [2]; improvement of the device control system [3]; search for the optimal design of the LCD modulator [4]. Usually, a high-speed LCD modulator is based on all kinds of structures $\pi$ - cells, in which LC structures with a zero or 180-degree twist angle are used, however, as recent works have shown, an LCD shutter in which an LCD with a twist angle of $270^{\circ}$ and antisymmetric boundary conditions on orienting surfaces. This short message is devoted to finding the optimal value of the control voltage for a high-speed LCD light modulator.

\section{Results}

The LCD shutter can operate in both birefringent and waveguide modes, however, a device operating in waveguide mode has a higher average contrast ratio over the spectrum. Typically, such a device contains an input polarizer, an LCD cell, a phase compensator, and an output polarizer located in series on one optical axis. The input polarizer with its maximum transmittance is oriented in the direction of rubbing on the input substrate, and the output polarizer is oriented in the direction of rubbing on the output substrate. The thickness of the $d_{L C}$ LC layer in the working cell is $3.5 \mu \mathrm{m}$. This thickness of the LC working layer was chosen because a decrease in $\mathrm{d}_{\mathrm{LC}}$ leads to a violation of the waveguide regime of the LC structure and greatly degrades the optical characteristics of the LC modulator, and an increase in $d_{L C}$ entails an increase in the response time of the device. Antisymmetric boundary conditions on the orienting cell substrates are due to the standard technology of rubbing the cell substrates, which provides the pre-tilt angle of the liquid crystal molecules on the input surface equal to $2^{\circ}$, and on the exit surface$-2^{\circ}$. The phase compensator is a uniaxial phase plate oriented at an angle of $28^{\circ}$ to the rubbing direction on the first substrate of the LC cell and having an optical thickness of $0.0345 \mu \mathrm{m}$. If no voltage is applied to the control electrodes, then the LC structure of the modulator is not distorted. In this case, the light passing through the input polarizer becomes linearly polarized and hits the LC cell. Since the LC structure is not distorted, it turns the plane of polarization of light by $270^{\circ}$ and the wave passes through the phase compensator and then through the output polarizer. Since the phase delay of the phase compensator is small, it very weakly distorts the linear polarization of the light wave passing through it, and therefore such a light wave completely passes through the output polarizer. In this case, the modulator has maximum transmission. If a high control voltage is applied to the control electrodes, then in this case the LC structure of the modulator 
becomes highly distorted and ceases to rotate the plane of polarization of the light transmitted through the crystal. Since the output polarizer is rotated $90^{\circ}$ relative to the input one, light does not pass through such an LCD cell. The phase compensator is used to convert elliptically polarized light emerging from a distorted LC structure into linearly polarized light with a polarization direction perpendicular to the direction of maximum transmission of the output polarizer. In this state, the LCD modulator has a minimum transmission that provides an image contrast ratio comparable to that of a standard twist modulator.

To study the behavior of the switching dynamics of the described LC modulator, we used the method of computer simulation using the MOUSE-LCD package [5]. The total response time $(\tau)$ of the LCD modulator is the sum of the on time $\left(\tau_{o n}\right)$ and off time $\left(\tau_{o f}\right):=\tau_{o n}+\tau_{o f f}$. The turn-on time is the time required for the LCD modulator to go from a state with zero control voltage to a state with a high control voltage. The turn-off time is the time required for the LCD modulator to make a reverse transition when the control voltage is switched from high to zero. In this case, the short response times of this LCD modulator are achieved due to three factors: 1) high values of control voltages; 2) antisymmetric boundary conditions in the structure; 3 ) small thickness of the LC cell. Analysis of the results of computer simulation showed that the dependence $\tau=\tau(U)$ with a $20 \%$ error can be approximated by a simple function:

$$
\tau=c+\frac{a}{U^{2}-b}
$$

where the constants $\mathrm{a}, \mathrm{b}$, and $\mathrm{c}$ depend on the physical constants of the LC and the boundary conditions in the LC cell (the twist angle of the structure, the pre-tilt angles of the LC molecules on the substrates). Such an analytical form of the dependence of the response time of an LCD device on the control one has been known for a long time for low control voltages, but later it was shown that it is also true for high values of control voltages. A significant difference in our case, from the previously obtained data, is the presence of a constant c, which limits the total response time from below and does not depend on the voltage. This means that a further increase in the control voltage does not lead to a decrease in the response time of the device. A few words should be said about the influence of the "backflow" on the relaxation time, which significantly affects the dynamics of switching off the LC modulator under symmetric boundary conditions. We carried out a computer simulation of the switching dynamics of an LC modulator with antisymmetric boundary conditions, and as a result, it was found that the relaxation time of such a device is the same with and without considering the "backflow". It can be assumed that the short response time of the LC modulator with antisymmetric boundary conditions can be explained by two factors: 1) antisymmetric boundary conditions in the LC cell, in which only half of the working gap thickness plays a role; 2) in the dynamics of switching between the two states in an LCD modulator with antisymmetric boundary conditions, there is no influence of the "backflow".

\section{Conclusion}

The performed computer simulation of the switching dynamics of a high-speed LC light modulator made it possible to find the analytical dependence of the total response time of the LC light modulator on the control voltage. Within the framework of this model, it is shown that there is a limiting value of the control voltage, upon reaching which its further increase does not lead to a decrease in the total response time of the device.

\section{References}

1. Jones Cliff J (2018) The fiftieth anniversary of the liquid crystal display. Liquid Crystals Today 27(3): 44-70.

2. Kamanina NV, Zubtsova Yu A, Toikka AS, Likhomanova SV, Zak A (2020) Temporal characteristics of a liquid crystal cell with WS2 nanoparticles: mesophase sensitization and relief features. Liq. Cryst. and their Appl 20(1): 34-40.

3. Geyvandov AR, Simdyankin IV, Barnik MI, Palto VS, Palto SP (2019) Fast mode in electro-optical switching of a liquid crystal cell with a decrease in the period of the electrode lattices. Crystallography 64(3): 407-411.

4. Simonenko GV (2020) Computer analysis of the influence of technological parameters of a high-speed liquid crystal modulator on its integral characteristics. Journal of Physics: Conference Series, 1560, 012028.

5. Chigrinov VG, Simonenko GV, Yakovlev DA, Podjachev Yu B (2000) The optimization of LCD electrooptical behavior using MOUSE - LCD software. Mol Crys Liq Crys 351: 17-25.

\section{Your next submission with Juniper Publishers will reach you the below assets}

- Quality Editorial service

- Swift Peer Review

- Reprints availability

- E-prints Service

- Manuscript Podcast for convenient understanding

- Global attainment for your research

- Manuscript accessibility in different formats

( Pdf, E-pub, Full Text, Audio)

- Unceasing customer service

Track the below URL for one-step submission

https://juniperpublishers.com/online-submission.php 